\title{
Brightness for different surround conditions: The effect of transient glare
}

\author{
LUIS ISSOLIO and ELISA M. COLOMBO \\ Universidad Nacional de Tucumán, Tucumán, Argentina
}

\begin{abstract}
We measured the effect of a transient glare source on the perceived brightness of a standard luminance $\left(\mathrm{L}_{\mathrm{STD}}\right)$ patch $\left(0.5 \mathrm{~cd} / \mathrm{m}^{2}\right)$ as a function of the surround luminance $\left(\mathrm{L}_{\mathrm{S}}\right)$. In the experiment, both increment and decrement stimuli were dependent on the value of the $\mathrm{L}_{\mathrm{S}}(0.01,0.2,0.4,0.6,0.8,1.0,1.5$, or $2.0 \mathrm{~cd} / \mathrm{m}^{2}$ ). We adopted a magnitude comparison paradigm using constant stimuli to determine the test matching luminance $\left(\mathrm{L}_{\mathrm{M}}\right)$. When $\mathrm{L}_{\mathrm{S}}$ was lower than the luminance of the patch, which corresponds to increments, $\mathrm{L}_{\mathrm{M}}$ was lower than $\mathrm{L}_{\mathrm{STD}}$, and this effect was highest for the lowest $\mathrm{L}_{\mathrm{S}}$. There was a small but noticeable cusp as increments shifted to decrements. As $\mathrm{L}_{\mathrm{S}}$ increased further (i.e., as the decrement grew), $\mathrm{L}_{\mathrm{M}}$ flattened out below $\mathrm{L}_{\mathrm{STD}}$. The overall pattern of results could be interpreted in terms of the concept of contrast brightness, with consideration of the intrinsic differences in brightness evaluations between decrements and increments.
\end{abstract}

The experiment we report here is part of a series designed to investigate the effects of the peripheral transient glare in scotopic-mesopic adaptation and suprathreshold tasks. We are particularly interested in the typical conditions of visual tasks during nighttime driving. The effect of such glare sources on motion perception was studied in our earliest works on this topic (Barraza \& Colombo, 2000, 2001). Then, considering that the perception of brightness $^{1}$ is an important part of human visual information processing, we proposed a methodology for brightness judgments (Colombo, Barraza, \& Issolio, 2000). In that article, we presented the results of an experiment in which just one surround luminance $\left(\mathrm{L}_{\mathrm{S}}\right)$ was used. We also examined the effect of transient glare in myopic subjects (Issolio, López-Gil, Colombo, \& Miró, 2001). In the present work, we study how the effect of transient glare on perceived brightness depends on $\mathrm{L}_{\mathrm{S}}$ in both decremental and incremental conditions.

A large amount of literature deals with the effects caused by the presence of a source of glare in the visual field, but in most cases experiments were performed with a steady glare using threshold tasks and photopic levels of adaptation luminances (for a review, see Vos, 1984). The light arising from a glare source is scattered in the ocular media, producing a veiling retinal illuminance that

The authors wish to acknowledge a fellowship to L.I. and PIP Gran 4948 from Consejo Nacional de Investigaciones Científicas y Técnicas, Grant 26/e112 to E.M.C. from Consejo de Investigaciones of Universidad Nacional de Tucumán, and Grant PICT13-15190 to E.M.C. from Agencia Nacional de Promoción Científica y Tecnológica. We thank José Barraza, Marina Bloj, and Andrew Derrington for their helpful comments on the manuscript, and Norberto López-Gil and Ignacio Miró for the pupil light reflex measurements. Correspondence concerning this article should be addressed to L. Issolio, Departamento de Luminotecnia, Luz y Visión, Facultad de Ciencias Exactas y Tecnología, Universidad Nacional de Tucumán, Av. Independencia 1800 (4000), Tucumán, Argentina (e-mail: lissolio@herrera.unt.edu.ar). reduces the retinal contrast of the stimulus. A quantifiable disability glare effect can be measured in terms of the veiling luminance (Holladay, 1927; Hood \& Finkelstein, 1986), which produces an elevation of foveal threshold. In real-life situations, potential glare sources are not steady; frequently, they present a transient temporal pattern. When detection thresholds are measured under glare conditions, the loss of sensitivity in the fovea produced by the sudden onset of a glare source is significantly greater than the effect from a steady glare source of the same illuminance (Bichão, Yager, \& Meng, 1995). This behavior has its correlation when the experiment is performed using a suprathreshold task such as the brightness evaluation: The greatest brightness reduction was found when the glare source was turned on (Issolio, Barraza, \& Colombo, 2006). Bichão, Meng, and Yager (1995) addressed the issue of night driving problems by including mesopic-scotopic levels in threshold tasks. They found similar results: The transient glare effect is significantly greater than the steady glare effect.

In recent years, there has been renewed interest in brightness and lightness constancy. However, according to Arend and Goldstein (1987), although the literature on brightness and lightness is vast, the majority of the reported experiments are ambiguous because they do not clarify whether their subjects matched brightness, lightness, or some combination of the two.

There are a few works on the effect of glare on brightness. Fry and Alpern (1953) studied the effect of a peripheral glare source on the brightness of an object. They developed an experiment based on a haploscopic arrangement. The right eye was shown a reference stimulus, and a comparison stimulus was presented jointly to the left eye with a steady glare source. The task was performed with a single dark background and several levels of glare. Fry and Alpern showed, with an empirical equation, that the brightness reduction becomes stronger as the glare level 
increases. This phenomenon was explained taking into account only the simultaneous contrasts. Whittle and Challands (1969) obtained similar results using several levels of background luminance as different veiling luminances. In our previously mentioned work (Colombo et al., 2000), we designed a more natural experimental setup in which a reference stimulus presented under transient glare conditions was compared sequentially with a similar test stimulus without glare. We presented the experimental results considering just one dark $\mathrm{L}_{\mathrm{S}}$. Results were adjusted by an equation of the type proposed by Fry and Alpern.

Gilchrist and Jacobsen (1983) made an important contribution to the study of the effect of veiling luminance. They found lightness constancy of seven decremental surfaces embedded in a complex, real-world scene when the surfaces were covered by a veiling luminance. These results challenged ratio and contrast theories because a veiling luminance, by adding a constant luminance to every point in the image, dramatically alters luminance ratios. Lightness constancy was not obtained, however, when these 3-D outdoor scenes were replaced by a simpler, flat display.

The results of Fry and Alpern (1953) and Colombo et al. (2000) could be explained, to some extent, by emphasizing the effects of luminance contrast, but also by considering the influence of context (Gilchrist \& Jacobsen, 1983).

It is well known that the perception of brightness and lightness - intensive dimensions - depends on both sensory and cognitive processes. First, there is a simple and coherent psychophysics of contrast, which includes the phenomena of simultaneous contrast and adaptation and reflects the contrast coding that is known as a prime function of early vision. Second, because of the variety of circumstances under which the contrast-coded signal can be seen, the higher levels of the visual system must use it differently in different contexts.

In the present work, we study the effect of disability glare on a brightness matching task considering different levels of $\mathrm{L}_{\mathrm{S}}$. We include several points as decrements in order to obtain a newer piece of evidence than that found in our previous experiment (Colombo et al., 2000). We used a central standard patch of fixed luminance $\left(0.5 \mathrm{~cd} / \mathrm{m}^{2}\right)$ with several surrounds (with luminances of $0.01-2 \mathrm{~cd} / \mathrm{m}^{2}$ ) in order to obtain incremental and decremental stimuli. The patches to be matched were seen against the same surround in order to evaluate only the effect of glare on the standard stimulus.

If we consider both increment and decrement stimuli, it might be possible to reconcile two traditions of work on lightness and brightness: one that has emphasized the effects of edge contrast and one that has downplayed them. We expect the glare effects to support the idea of both a low-level process - contrast coding - and a high-level process that would imply some kind of parsing of the scene in which the glare must be differentiated from the reflectance as well as from the illumination as a whole. Moreover, the glare source in the peripheral field could be a fundamental element of the spatial layout that would help us to analyze the scene. This analysis is the key to understanding which situations yield contrast brightness (explained largely in terms of retinal processes) and which do not (which can be understood mostly in terms of higher level processes). Much of the glare effect is probably local, but there must be a global mechanism if consistency over the entire scene is to be achieved. How good are we at judging lighting and, more specifically, at judging a glare source and the surface gray level as complementary aspects that complete our perception of the real world?

\section{METHOD}

\section{Observers}

Three observers were tested. All had normal acuity. Author L.I. (a 33-year-old male) was knowledgeable about the experimental paradigm and had prior experience in making brightness judgments. Observers M.I.M. (a 27-year-old female) and R.A. (a 26-year-old male) were not experienced observers and were naive regarding the experimental design.

\section{Apparatus}

Achromatic patterns were generated using an RGB framestore, which was part of a purpose-built display controller, the Cambridge Research System's VSG2/3. VSG2/3 has two palette chips operating in parallel. When the two palette outputs with different gains are added together, a higher resolution output is obtained. This operating mode produces the effect of 12 bits of gray-level resolution per pixel, which was used to attain a more precise control of luminance. The stimulus was displayed on an EIZO T560i-T monitor. The monitor was gamma corrected over the luminance range used in the experiments, providing a luminance resolution of $0.01 \mathrm{~cd} / \mathrm{m}^{2}$.

The glare source was an incandescent lamp whose intensity was regulated by neutral density filters. The lamp was located $10^{\circ}$ away from the observer's line of sight, at the height of the patch. An electronic shutter with a $1.5^{\circ}$ aperture controlled the onset and offset of

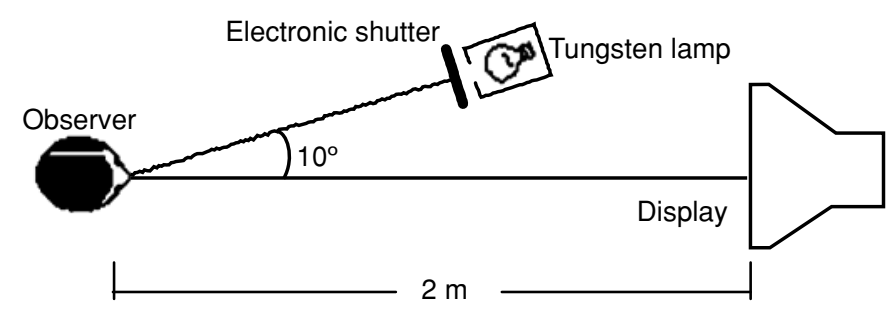

Figure 1. Schematic illustration of the layout of the experimental apparatus. 
the glare. Figure 1 shows a diagram of the layout of the experimental apparatus.

\section{Binocularity and Natural Pupil}

Brightness perception is typically measured by using haploscopic experimental setups (Fry \& Alpern, 1953; Whittle \& Challands, 1969) or by means of a simultaneous binocular viewing of the two to-be-matched stimuli (Arend, 1993; Arend \& Goldstein, 1987; Schirillo, 1999). In this work, we have used neither the haploscopic arrangement nor simultaneous binocular viewing. The former was rejected because we wanted to recreate a real-life viewing condition. The latter was not used because in our experiment the standard and comparison stimuli could not be presented simultaneously, since glare had to be applied only to the standard. Hence, we presented the two to-be-matched stimuli sequentially (Colombo et al., 2000).

The screen was viewed binocularly with the head positioned on a chinrest. The observers maintained natural pupils and accommodation throughout the experiment, so it was necessary to know the latency of the pupil to establish the same pupil diameter in the viewing of both standard and comparison patterns. In some studies, the pupil's light reflex was evaluated, but we made our own measurements under the same experimental conditions on a 4th subject who did not participate in the main experiment. Pupil diameter was determined from an image recorded with a CCD camera. Figure 2 shows the evolution of the pupil diameter due to the presence of the glare source. After the glare source was turned on, there was a

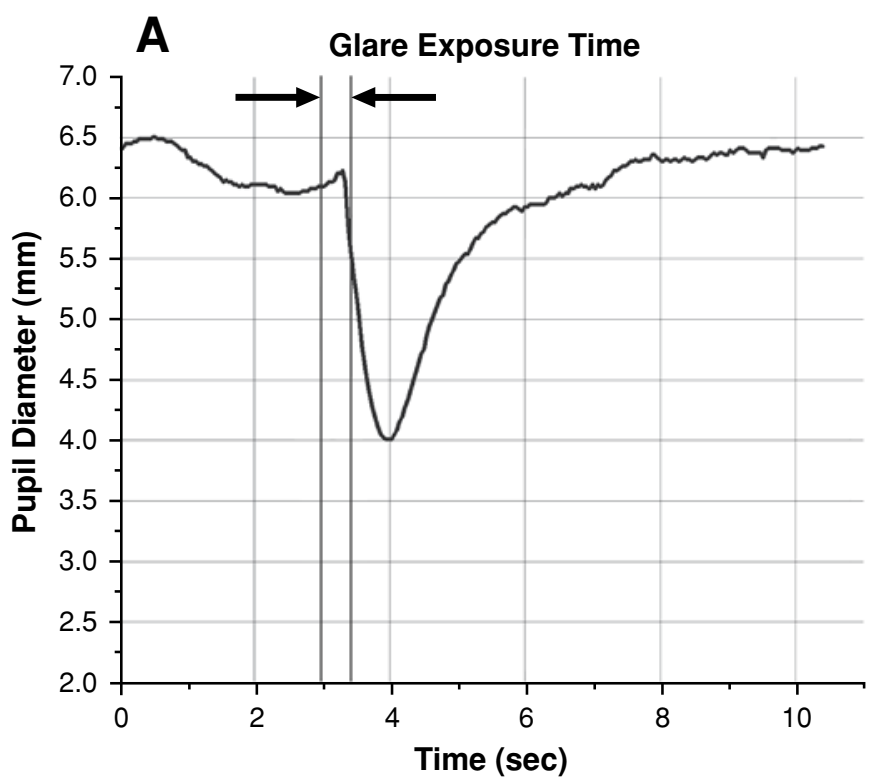

B

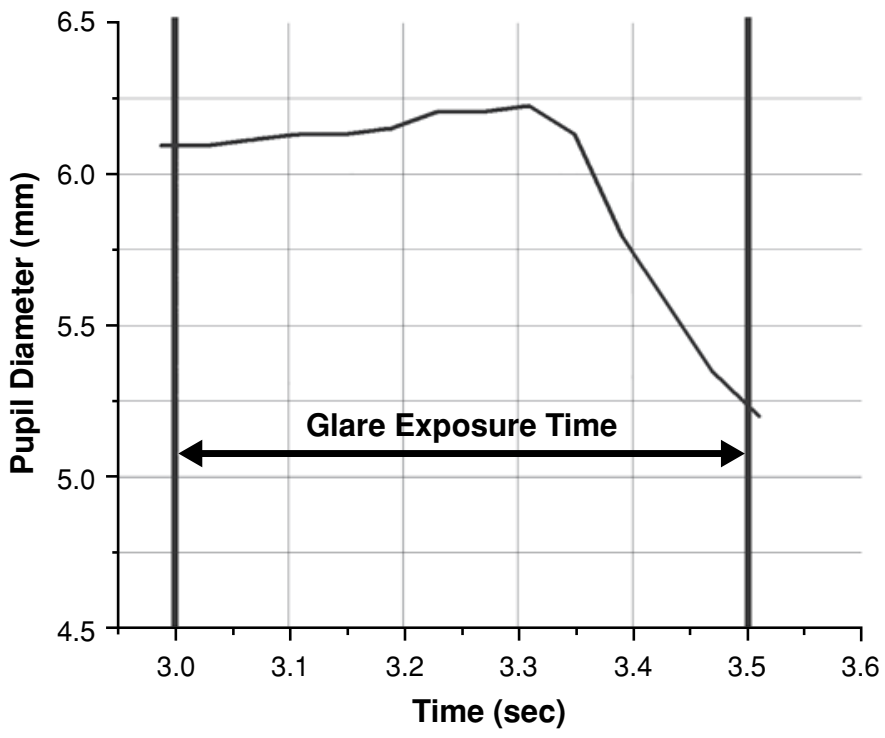

Figure 2. Change in pupil diameter measured with a CCD camera in an observer against a glare condition of the same geometry, intensity, and duration as that used in the main experiment. (A) Evolution of the pupil diameter before, during, and after exposure to the glare source. (B) A detail of pupil behavior during the exposure to glare. 
300 -msec latency and then the pupil diameter started to reduce by about $2 \mathrm{~mm}$. This value is similar to those found by Bitsios, Prettyman, and Szabadi (1996), who measured latencies for groups of young and elderly subjects and did not find significant differences between them. Bergamin and Kardon (2003) also found these latencies in right and left pupils simultaneously, and Barbur (2004) found them for different levels of stimulation. In our experiment, the pupil took approximately $5 \mathrm{sec}$ to fully recover once the glare source was turned off.

\section{Stimuli}

The stimuli were round patches of uniform luminance, $4^{\circ}$ in diameter, placed in the center of the monitor. The remainder of the display area $\left(7^{\circ} \times 9.5^{\circ}\right)$ was set to the $\mathrm{L}_{\mathrm{S}}$, and the monitor was located in a dark room at a viewing distance of $2 \mathrm{~m}$.

The cathode-ray tube displayed two patches sequentially: the comparison $\left(\mathrm{L}_{\mathrm{C}}\right)$ patch with a luminance of one of the six values selected in a predetermined interval, and the standard luminance $\left(\mathrm{L}_{\mathrm{STD}}\right)$ patch, which always had a luminance of $0.5 \mathrm{~cd} / \mathrm{m}^{2}$. For both patches, $\mathrm{L}_{\mathrm{S}}$ was the same and was kept constant during each experimental session. The $\mathrm{L}_{\mathrm{S}} \mathrm{s}$ were $0.01,0.2,0.4,0.6,0.8,1.0,1.5$, and $2.0 \mathrm{~cd} / \mathrm{m}^{2}$, so for $\mathrm{L}_{\mathrm{S}} \mathrm{s}$ above $0.5 \mathrm{~cd} / \mathrm{m}^{2} \mathrm{~L}_{\mathrm{STD}}$ was a decrement, and for lower $\mathrm{L}_{\mathrm{S}} \mathrm{S}$ it was an increment.

The glare source was turned on simultaneously with the $\mathrm{L}_{\mathrm{STD}}$ and was kept on for $500 \mathrm{msec}$ on each trial. The illuminance produced at a point between the two pupil centers was $601 \mathrm{x}$. Each stimulus was presented during $300 \mathrm{msec}$ with abrupt onset and offset; thus, the standard was viewed while the pupil was unaffected by the glare. The interstimulus interval was $1.2 \mathrm{sec}$, and the intertrial interval was $5 \mathrm{sec}$ in order to allow the pupil to recover its diameter. After presentation of the stimuli, the observer responded, and there was no time limitation. Figure 3 shows the time course of the presentation of the stimuli and the glare source in a trial. Before each session, the observers were adapted to the experimental conditions for $5 \mathrm{~min}$. In spite of the high level of illuminance produced by the glare source, the short time during which it stayed on produced in the corresponding retinal area a (nonsignificant) $0.01 \%$ photopigment bleaching (Blakemore \& Rushton, 1965).

Glare illuminance was measured with a Minolta T-1M illuminance meter, and stimulus luminance was measured with an LMT L1009 luminance meter.

\section{Procedure}

A magnitude comparison paradigm with the method of constant stimuli was used. On each trial, there were two intervals. In the first, the $\mathrm{L}_{\mathrm{C}}$ patch was displayed, and in the second the $\mathrm{L}_{\mathrm{STD}}$ patch was displayed under transient glare conditions. The observer's task was to indicate, by pressing a key, which of the two patches appeared brighter-that is, which had the greater apparent luminance. Six values of $\mathrm{L}_{\mathrm{C}}$ were randomized and balanced. For each value of $\mathrm{L}_{\mathrm{C}}$, 52 observations were completed in two blocks. The experiment was run for each of the eight different $\mathrm{L}_{\mathrm{S}} \mathrm{s}$.

A control experiment was performed to check the methodology. It was exactly the same as the main experiment, but the task of matching luminance was performed without glare.

\section{RESULTS}

We fitted Weibull functions to our measured response distributions and found the point of subjective equality (matching luminance, or $\mathrm{L}_{\mathrm{M}}$; for a review of the procedure, see Macmillan \& Creelman, 1991).

In Figure 4, the $\mathrm{L}_{\mathrm{M}}$ values are plotted as a function of $\mathrm{L}_{\mathrm{S}}$ for each observer with and without glare.

The obtained data from the measures performed without glare show constancy of $\mathrm{L}_{\mathrm{M}}$ around $\mathrm{L}_{\mathrm{STD}}$, as was expected.

When the luminance of the surround was lower than that of the patch (which corresponds to increments), $\mathrm{L}_{\mathrm{M}}$ was lower than $\mathrm{L}_{\mathrm{STD}}$, and this effect was greatest at the lowest $\mathrm{L}_{\mathrm{S}}$. Then, there was a small but noticeable cusp as increments shifted to decrements. As $\mathrm{L}_{\mathrm{S}}$ increased further (i.e., as the decrement became larger), $\mathrm{L}_{\mathrm{M}}$ flattens out below $\mathrm{L}_{\mathrm{STD}}$. The measurement was not performed for an $\mathrm{L}_{\mathrm{S}}$ of $0.5 \mathrm{~cd} / \mathrm{m}^{2}$ because the stimulus contrast would be zero, but curves for the 3 observers cross at an $\mathrm{L}_{\mathrm{M}}$ of $0.5 \mathrm{~cd} / \mathrm{m}^{2}$, indicating a null effect of glare.

The aforementioned small but noticeable cusp (Figure 4) would be a manifestation of the crispening effect. The observers saw a sharp change in the brightness of the stimulus when its luminance passed through that of the surround. In this way, the contrast of the stimulus was perceptually magnified when its luminance was close to $\mathrm{L}_{\mathrm{S}}$ (Whittle, 1992). This phenomenon is represented in Figure 5, where the slope values at the point of equality of the psychometric curves under the glare condition are plotted as a function of $\mathrm{L}_{\mathrm{S}}$. The graph shows a remarkable increment for surrounds of 0.4 and $0.6 \mathrm{~cd} / \mathrm{m}^{2}$, corresponding to the smallest contrasts for the 3 observers.

\section{DISCUSSION}

To our knowledge, this is the first study in which increments and decrements, transient glare, and scotopicmesopic conditions are specifically considered in a brightness matching task. We showed how the same constant glare source affects the perceived brightness of a patch (also of constant luminance throughout the experiment) as a function of changes in $\mathrm{L}_{S}$. It must be pointed out that our matching procedure differs from that normally employed in experiments on brightness perception, because in our experiment the surround of the matching stimulus changes along with that of the test stimulus. Thus, we can measure the effect of the disability glare on the perceived brightness as $L_{S}$ changes for both the standard and comparison

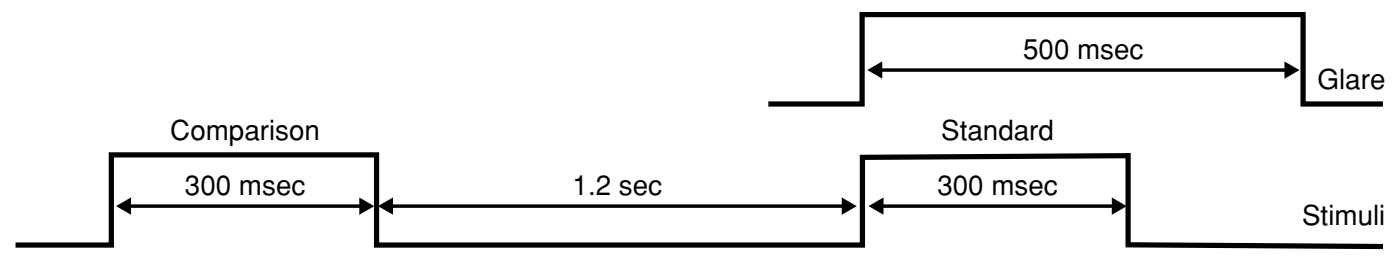

Figure 3. Time line of the presentation of the stimuli and glare. The surround is constant during each experimental session. 

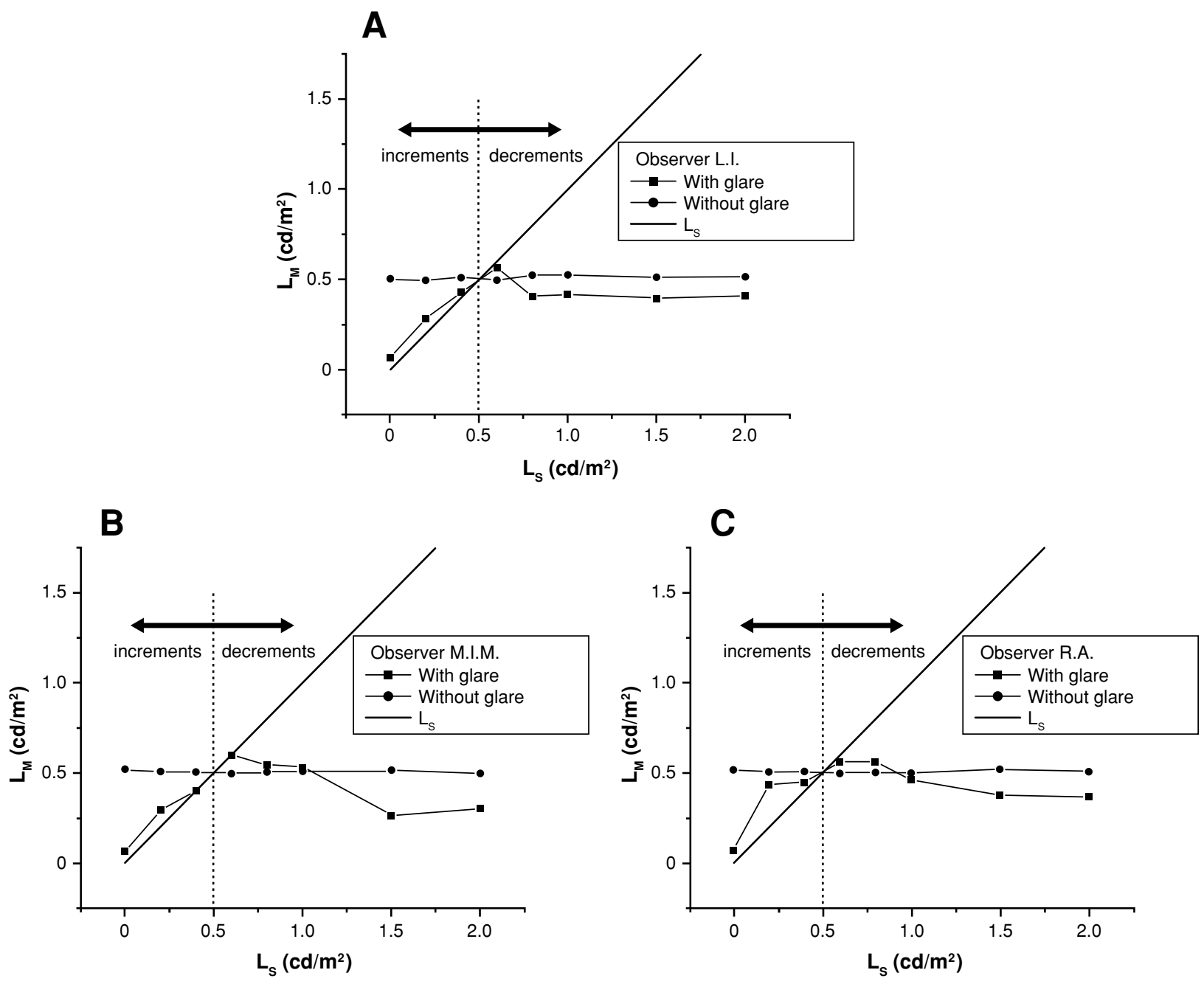

Figure 4. Matching luminance $\left(L_{M}\right)$ as a function of surround luminance $\left(L_{S}\right)$. Results obtained with and without glare condition are shown for Observers L.I. (A), M.I.M. (B), and R.A. (C). The vertical dotted line $\left(L_{S}=0.5 \mathrm{~cd} / \mathrm{m}^{2}\right)$ divides increments and decrements. The slope of the diagonal line represents the case in which $L_{M}=L_{S}$. The curves of the 3 observers cross their point of intersection.

stimuli. For example, the crispening effect operates on the comparison stimulus as well as on the standard stimulus, whereas it is not apparent in the nonglare data.

It is interesting to note that replotting the data representing the ratio between $L_{M}$ and $L_{S}$ as a function of $L_{S}$ yields additional information, presented in Figure 6. In this figure, we include a set of prediction lines: one that shows what the results would look like if the subjects performed luminance matching, one showing the results if they performed ratio matching, and one showing results if they exhibited lightness constancy (i.e., if the subjects discounted the glare). These three lines were calculated using the ratios presented below.

For luminance matching,

$$
\frac{\mathrm{L}_{\mathrm{STD}}+\mathrm{L}_{\mathrm{V}}}{\mathrm{L}_{\mathrm{S}}}
$$

for ratio matching,

$$
\frac{\mathrm{L}_{\mathrm{STD}}+\mathrm{L}_{\mathrm{V}}}{\mathrm{L}_{\mathrm{S}}+\mathrm{L}_{\mathrm{V}}}
$$

and for lightness constancy,

$$
\frac{\mathrm{L}_{\mathrm{STD}}}{\mathrm{L}_{\mathrm{S}}},
$$

where $\mathrm{L}_{\mathrm{V}}$ is the veiling luminance produced by the glare source, which in most studies is computed using the socalled Stiles-Holladay formula for a foveal region:

$$
\mathrm{L}_{\mathrm{V}}=\frac{10 \mathrm{E}}{\theta^{2}}
$$

where $\mathrm{E}$ is the illuminance on the eye and $\theta$ is the angular position of the glare source with respect to the line of vi- 


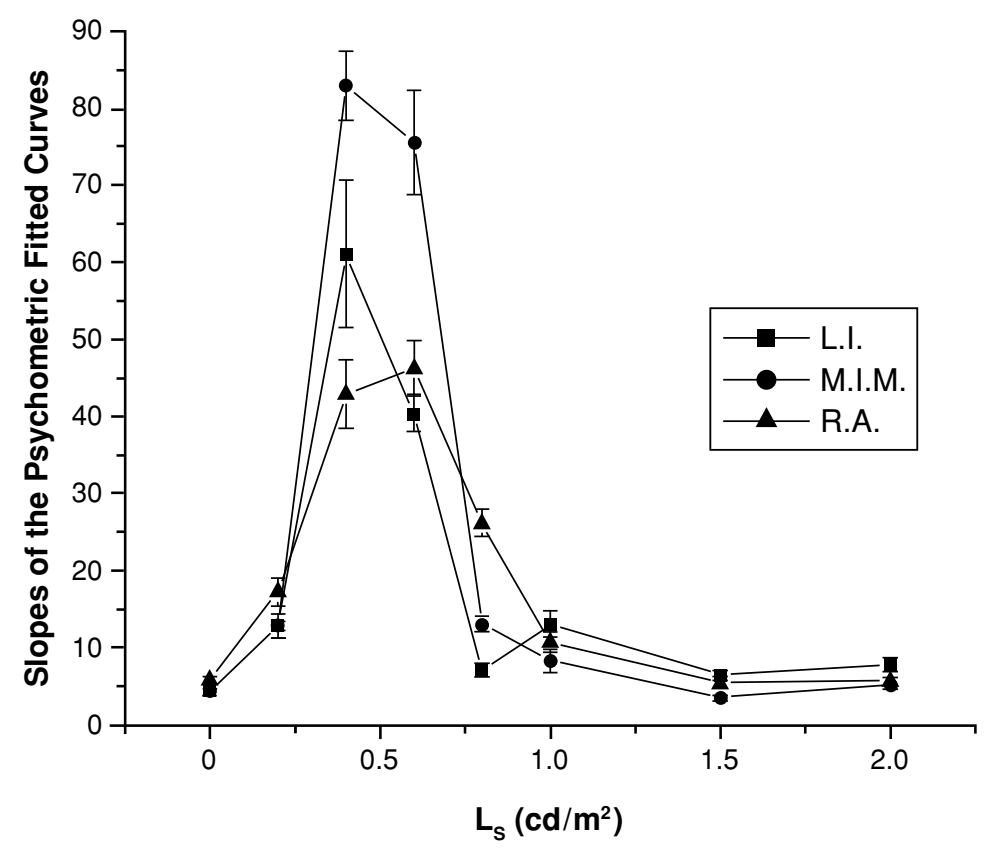

Figure 5. Slopes of the psychometric curves, obtained for $63.5 \%$ of the range of the Weibull psychometric curves, as a function of surround luminance $\left(L_{S}\right)$. Results obtained from each of the 3 observers are shown.

sion (Vos, 1984). For an $\mathrm{E}$ of $60 \mathrm{~lx}$ and a $\theta$ of $10^{\circ}, \mathrm{L}_{\mathrm{V}}$ is equal to $6 \mathrm{~cd} / \mathrm{m}^{2}$.

The ratio matching was computed by adding this veiling luminance to both patch and surround, and the ratio for luminance matching was computed by adding this veiling luminance only to the patch of the stimulus. Different investigations show the importance of correcting these ratio values when using any quantitative model of brightness (Stiehl, McCann, \& Savoy, 1983) and for the analysis of a variety of different contrast phenomena (McCann, 1998).

Figure 6 serves as the basis for a theoretical discussion. The results are especially significant in light of several studies that show differences in brightness evaluations between increments and decrements. Increments fall between the predictions of ratio matching and lightness constancy, although they fall closer to the prediction line for ratio matching, as was expected (Colombo et al., $2000)$. For the lowest contrast values $\left(\mathrm{L}_{\mathrm{S}} \mathrm{s}\right.$ of $0.4 \mathrm{~cd} / \mathrm{m}^{2}$ and $0.6 \mathrm{~cd} / \mathrm{m}^{2}$ ), plotting shows a change of the slope toward the ratio match prediction, which indicates a contrast coding (Whittle, 1992). Finally, however, the dramatic finding is that as the decrements get larger, $\mathrm{L}_{\mathrm{M}}$ flattens out below what would be considered lightness constancy, indicating a type of constancy independent of veiling luminance. These results agree with those relative to decrements obtained by Gilchrist and Jacobsen (1983) using a 3-D display.

Even though our experiment was concerned with brightness, which is apparent luminance, the experimental data are very much from below the corresponding luminance matching line, which means that the observers did not evaluate the absolute luminance either for increments or for decrements.

The present results could be explained by considering the framework provided by Whittle (1994b) when the contrast dependence of brightness and lightness judgments (contrast brightness) under very restricted conditions is related to vision under more normal conditions. However, for a complete understanding of the cause of the difference in brightness evaluations between increments and decrements, it is necessary to take into account also the crucial fact that decrements have an absolute (zero) point, whereas increments do not.

Like the four studies considered by Whittle (1994a), our experiment provides a halfway house between ordinary seeing and the restricted conditions under which contrast brightness is most reliably demonstrated. In our study, brightness matches were made between patches in surrounds. For decrements, our data are most compatible with contrast brightness for lightness matches between patches in surrounds of the same reflectance under different illuminations, even though in our case the presence of the glare source alters luminance ratios. However, due to the fact that the patch is the "black limit" and remains more or less dark for the different values of $\mathrm{L}_{\mathrm{S}}$, lightness constancy is obtained (Whittle, 1994b). For increments, as in the four studies mentioned above, the brightness is most strongly determined by local luminance contrast. Results are closer to the line for ratio match even though they show a shift to lightness constancy. In this situation, the surround gives the "black limit," and this value sets the minimum. 


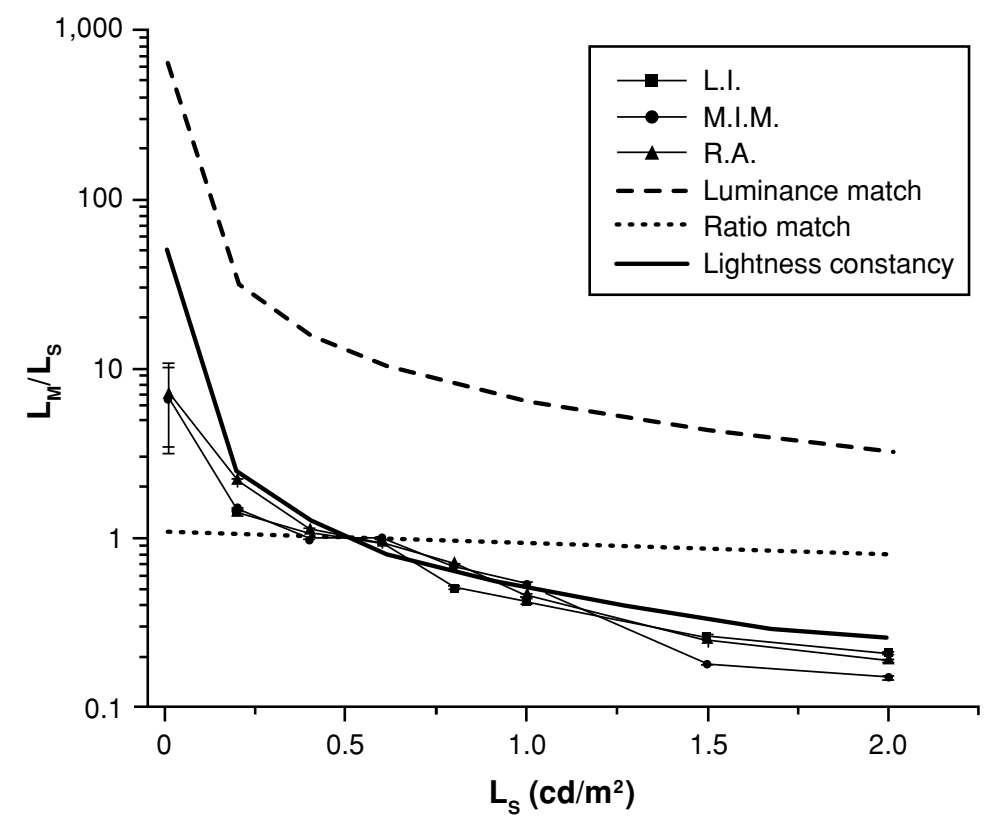

Figure 6. Ratios between the matching luminance $\left(L_{M}\right)$ and the surround luminance $\left(L_{S}\right)$ as a function of $L_{S}$ for the 3 observers. Prediction lines of luminance match, ratio match, and lightness constancy are included.

Thus, there is a relatively simple core structure: The brightness and lightness match depends on the contrast, which in turn depends on the sensory processes of early vision. On the other hand are the effects on lightness and brightness of the higher level perceptual processes that break the scene down into object, lighting, and spatial layout - central patch and peripheral glare source. Although a partition into "sensory" and "perceptual" processes is not a novel idea, our results confirm two slightly unusual things about this concept in the contexts of brightness and lightness. The first is its primary dependence on contrast, and the second is its acceptance that even the elementary visual sensation of brightness depends on global as well as local contexts.

\section{REFERENCES}

Adelson, E. H. (1993). Perceptual organization and the judgment of brightness. Science, 262, 2042-2044.

Arend, L. E. (1993). Mesopic lightness, brightness, and brightness contrast. Perception \& Psychophysics, 54, 469-476.

Arend, L. E., \& Goldstein, R. (1987). Simultaneous constancy, lightness, and brightness. Journal of the Optical Society of America A, 4, 2281-2285.

BARBUR, J. L. (2004). Learning from the pupil: Studies of basic mechanisms and clinical applications. In L. M. Chalupa \& J. S. Werner (Eds.), The visual neurosciences (Vol. 1, pp. 641-656). Cambridge, MA: MIT Press.

BARRAZA, J. F., \& COLOMbo, E. M. (2000). Transient glare: Its effect on the lower threshold of motion. Optics Express, 7, 172-177.

Barraza, J. F., \& Colombo, E. M. (2001). The time course of the lower threshold of motion during rapid events of adaptation. Vision Research, 41, 1139-1144.

BERGAMin, O., \& Kardon, R. (2003). Latency of the pupil light reflex: Sample rate, stimulus intensity, and variation in normal subjects. Investigative Ophthalmology \& Visual Science, 44, 1546-1554.

Bichão, I. C., Meng, J., \& Yager, D. (1995). Temporal and spatial as- pects of disability glare: Simulation of nighttime driving [Abstract]. Investigative Ophthalmology \& Visual Science, 36, 1940.

Bichão, I. C., Yager, D., \& Meng, J. (1995). Disability glare: Effects of temporal characteristics of the glare source and of the visual-field location of the test stimulus. Journal of the Optical Society of America $A, \mathbf{1 2}, 2252-2258$.

Bitsios, P., Prettyman, R., \& Szabadi, E. (1996). Changes in autonomic function with age: A study of pupillary kinetics in healthy young and old people. Age \& Ageing, 25, 432-438.

Blakemore, C. B., \& Rushton, W. A. H. (1965). Dark adaptation and increment threshold in a rod monochromat. Journal of Physiology, 181, 612-628.

Colombo, E. M., Barraza, J. F., \& Issolio, L. (2000). Effect of a brief exposure to glare on brightness perception in the scotopic-mesopic range. Lighting Research \& Technology, 32, 65-69.

Fry, G. A., \& ALPERN, M. (1953). The effect of peripheral glare source upon the apparent brightness of an object. Journal of the Optical Society of America, 43, 189-195.

GiLCHRIST, A. L., \& JACOBSEN, A. (1983). Lightness constancy through a veiling luminance. Journal of Experimental Psychology: Human Perception \& Performance, 9, 936-944.

Holladay, L. L. (1927). Action of a light-source in the field of view in lowering visibility. Journal of the Optical Society of America, 14, 1-15.

Hood, D. C., \& Finkelstein, M. A. (1986). Sensitivity to light. In K. R. Boff, L. Kaufman, \& J. P. Thomas (Eds.), Handbook of perception and human performance (Vol. 1, pp. 5-1 to 5-3). New York: Wiley.

Issolio, L. A., BARRAZA, J. F., \& Colombo, E. M. (2006). Time course of brightness under transient glare condition. Journal of the Optical Society of America A, 23, 233-238.

Issolio, L. [A.], López-Gil, N., Colombo, E. M., \& Miró, I. (2001). Brightness perception under transient glare conditions with myopic observers wearing contact lenses and spectacles. Proceedings of SPIE, 4419, 557-560.

Macmillan, N. A., \& Creelman, C. D. (1991). Detection theory: A user's guide. Cambridge: Cambridge University Press.

McCann, J. J. (1998). Analysis of contrast experiments when corrected for intraocular scatter. Perception, 27, 84.

SchiRILlo, J. A. (1999). Surround articulation: I. Brightness judgments. Journal of the Optical Society of America A, 16, 793-803.

Stiehl, W. A., McCanN, J. J., \& Savoy, R. L. (1983). Influence of in- 
traocular scattered light on lightness-scaling experiments. Journal of the Optical Society of America, 73, 1143-1148.

Vos, J. J. (1984). Disability glare: A state of the art report. CIE Journal, 3, 39-53.

Whittle, P. (1992). Brightness, discriminability and the "crispening effect." Vision Research, 32, 1493-1507.

Whittle, P. (1994a). Contrast brightness and ordinary seeing. In A. L. Gilchrist (Ed.), Lightness, brightness, and transparency (pp. 111-157). Hillsdale, NJ: Erlbaum.

WhitTle, P. (1994b). The psychophysics of contrast brightness. In A. L. Gilchrist (Ed.), Lightness, brightness, and transparency (pp. 35-110). Hillsdale, NJ: Erlbaum.

Whittle, P., \& Challands, P. D. C. (1969). The effect of background luminance on the brightness of flashes. Vision Research, 9, 1095-1110.

\section{NOTE}

1. We follow the customary terminology: Brightness refers to the apparent luminance of the patch in the image itself, whereas lightness refers to the apparent reflectance of a surface in the scene (Adelson, 1993; Arend \& Goldstein, 1987). Moreover, these definitions imply the use of different experimental tasks. Spanish (the authors' native language) has only one word (claridad) to refer to both attributes, and for this reason it is worthwhile briefly to distinguish between brightness and lightness as apparent luminance and apparent reflectance, respectively.

(Manuscript received October 1, 2004;

revision accepted for publication July 27, 2005.) 